\title{
Ethics, Morality and the Formation of cultural studies intellectuals \\ GARY WICKHAM
}

\section{- InTRODUCTION}

In his admirably cautious historical survey of the development of cultural studies, British Cultural Studies, Graeme Turner describes the field as having 'no orthodoxy', being 'predominantly a critical field'. Neither 'discrete' nor 'homogeneous', he continues, cultural studies insists it is interdisciplinary, dealing with 'phenomena and relationships ... not accessible through the existing disciplines', a point to which we return. ${ }^{1}$ In setting out the by-now familiar story of cultural studies' emergence in Britain, Turner highlights, among other things, three elements of relevance to my argument: one, the pioneering work of Richard Hoggart, Raymond Williams, EP Thompson and Stuart Hall; two, the overwhelming influence of Marxism, with a focus on ideology and a critique of 'economism', featuring Althusser's reading of ideology, in an often complex relationship with Gramsci's notion of hegemony; and three, a commitment to at least some aspects of traditional British empiricism, as is evidenced in histories of popular movements of the nineteenth and twentieth centuries and in accounts of the operation of various media. ${ }^{2}$ Turner argues that from its earliest stages cultural studies featured a critical focus on the aesthetic, rejecting the idea that culture refers only to the aesthetic of a social elite, insisting, instead, that the focus of the study of culture should be on 'working-class culture and communities', in their 'everyday' and 'ordinary' forms. ${ }^{3}$

This sketch, presenting as it does a handful of widely agreed components of the cultural studies enterprise, is sufficient for present purposes. This article is not so much concerned with the history of the field as with the way in which aspects of its history are used in forming a particular type of cultural studies intellectual, one for whom ethics is subsumed 
into a morality directed to the necessity of engaging in a politics of empowerment. The article's concern, this is to say, is to problematise the taken-for-grantedness of this type of intellectual, something it seeks to do through a genealogy (in something like the Foucaultian sense of that term), or at least the outline of a genealogy.

A couple of examples will help bring the target into sharper focus. In the introduction to their monumental textual attempt to capture the flavour of the 1990 'Cultural Studies Now and in the Future' conference, editors Lawrence Grossberg, Cary Nelson and Paula Treichler seek to address the history of the field only in terms of its future, particularly in terms of its 'special intellectual promise', as it pursues what can only be called a quest: 'to cut across diverse social and political interests and address many of the struggles within the current scene'. ${ }^{4}$ In leading up to their historical remarks they stress the following features of cultural studies, all of which they see as aiding its quest: the diversity of its potential objects; the rich possibilities that flow from borrowing a plethora of methods from other fields, proudly owning no methods of its own; the openness provided by interdisciplinarity-'open to unexpected, unimagined, and even uninvited possibilities' - a benefit not sullied by the difficulty of defining the key term 'culture'; and, especially, the determination to 'make a difference', being about 'political critique' as much as it is about intellectual analysis. ${ }^{5}$ The contours of their historical remarks can easily be guessed from this preamble. The British tradition is embraced, but not without criticisms for its supposed political shortcomings-its initial focus on white working-class male culture at the expense of a concern for women and non-whites. The aspects of this tradition that the authors regard as more politically useful are lauded, especially the focus on popular culture and the 'complex negotiations with Marxism'. And, of course, the British focus on power and commitment to 'struggle' are endorsed as weapons in the fight to 'empower' the 'disempowered'. ${ }^{6}$

The ideal for cultural studies intellectuals that Nelson, Treichler and Grossberg employ in their introduction is clear enough. An ethics concerned with intellectual flexibility is subsumed into a particular morality, and the politics associated with it. The morality here is not about a clash between good and evil, but about empowering the disempowered. In short, cultural studies intellectuals, as these authors would have them formed, are flexible, through their interdisciplinary and open minds, and, crucially, willing and able to direct those minds to the cultural struggles involved in the politics of empowering the disempowered, whatever form those struggles may take.

This path for cultural studies intellectuals is also assumed in another essay in the Grossberg, Nelson and Treichler collection, an essay by one of the field's pioneers, Stuart Hall. ${ }^{7}$ Hall too does not want the entire British history of the field put on a pedestal; he also thinks the early model politically limited. As such, he draws on only aspects of its history, focusing on the role of theory in what cultural studies might achieve politically. For Hall, who allows the 
morality mentioned above to become one with the politics associated with it, a central role for theory is to inculcate in the cultural studies practitioner a sense of politics as engaged politics, even an 'angry' politics, on behalf of the disempowered. In a biographically charged account he assesses some of the theoretical frameworks he has personally encountered in his time as a cultural studies practitioner-Marxism in general, the Althusserian version, the Gramscian version, race theory and feminist theory, among others- to see how and in what ways they have contributed to this duty (some fare better than others, but all are appreciated). Cultural studies, he tells us, at least twice, is 'serious', even 'deadly serious', precisely in being engaged in the politics of empowerment. ${ }^{8}$ He adds an argument to the effect that such an engagement cannot be undertaken by individuals acting alone, it must be part of a 'movement', for it is movements that 'provoke' the 'theoretical moments' so important to keeping the whole process going. ${ }^{9}$ To be a 'serious' cultural studies intellectual, it follows, the ethical direction any practitioner needs to take must be a moral direction—ethics cannot be allowed to wander away from morality - the morality involved being expressed as political engagement, in a movement, on behalf of the disempowered.

It needs to be stressed at this early stage that in criticising one type of cultural studies intellectual I am not criticising the entirety of cultural studies. In a way this is obvious, for the space to criticise would not exist were the entire field given over to the work of only the ethical-must-be-moral type of intellectual. At least one alternative type does exist-the history of which is explored later in the piece-and there is plenty of evidence of its existence. In other words, while the ethical-must-be-moral type of cultural studies intellectual is undoubtedly the dominant type, there is a good deal of work produced in the field without the influence of the thinking informing this type-for example, to name just a handful at the monograph level, Turner's British Cultural Studies; Ian Hunter's two books Culture and Government and Rethinking the School, which seek to align the study of culture with an ethos of respecting, even serving, the modern state, especially via schooling; Mary Poovey's Making a Social Body, a historical account of culture in terms of the formation, separation and operation of related but distinct domains, especially 'the social', 'the economic' and 'the theological'; and Tony Bennett's Culture: A Reformer's Science, which attempts to understand culture and cultural studies in terms of a 'pragmatics' of government, particularly in terms of the formation and delivery of policy. ${ }^{10}$

In the first main section of this essay I outline, as the means of problematising the takenfor-grantedness of the ethical-must-be-moral type of cultural studies intellectual, a genealogy of this type of intellectual. This outline focuses first on the type's foundation in seventeenthcentury metaphysical philosophy, especially its reliance on the figure of homo-duplex, and then moves on to consider the way this foundation provided a springboard for the emergence of powerful aesthetic-hermeneutic and romantic elements, as central features of the formation 
of this type of intellectual. The outline is drawn from a variety of sources, but two sources merit special mention, both by Hunter: his Rival Enlightenments: Civil and Metaphysical Philosophy in Early Modern Germany, and his 'Aesthetics and Cultural Studies' essay in the Grossberg, Nelson and Treichler collection, which locates the anti-aesthetics approach to cultural studies —one of the markers of the field, as Turner showed us above-as a practice of cultivation (ultimately cultivating an aesthetics of anti-aesthetics). ${ }^{11}$ The main factor behind the heavy reliance on Hunter's work, besides its obvious scholarly quality, is the effectiveness with which it breaks the nexus between ethics and morality, allowing a different understanding of ethics to come to the fore, along with a different understanding of politics. In the second main section I identify-in terms of Hunter's evidence about the great early-modern rival to metaphysical thinking, civil philosophy—some historical features of the alternative to the ethical-must-be-moral type of cultural studies intellectual discussed briefly above, that is, the rival type that is allowing the present problematisation of the ethical-must-bemoral type, by this stage called 'the civil philosophy type'. The conclusion directly compares, in the cultural studies context, the two distinct types of intellectual.

One other preliminary point is necessary by way of clarification. In describing some cultural studies intellectuals as those for whom an ethical position is necessarily a moral position, this article does not seek to reveal some deeply hidden secret. An attempt to outline a genealogy is not an attempt to destroy through revelation. The arguments presented here accept that cultural studies was formed and is practised as a moral discourse. This is what it does. Even in offering, later, an account of a rival to the ethical-must-be-moral type I do not aim to 'unseat' cultural studies as a moral discourse. I do no more, and, it is hoped, no less, than participate in the recovery of an historically available means of differently relating the ethical to the moral, one that may be of intellectual value to the readers of Cultural Studies Review.

\section{— A genealogical outline of the ethical-MUST-Be-moral type}

The foundation of the ethical-must-be-moral type of intellectual is to be found in seventeenthcentury metaphysical philosophy, especially in the figure of homo-duplex. As Hunter describes it in Rival Enlightenments, the homo-duplex component of this type of intellectual is a Platonic and Aristotelian premise (especially Platonic) by which humans are understood to have two natures. One is a sensuous nature, by which we experience empirical realities, the other a rational or intelligible nature, by which we reason, crucially allowing us the capacity to rise above our 'other', baser, empirical nature. ${ }^{12}$ Referring to it, or at least to a key aspect of it, by the term 'quasi-Platonic moral cosmology', Hunter traces this component from its seventeenth-century Christian-metaphysical expression in the work of Gottfried Wilhelm Leibniz through to its expression in the eighteenth-century work of Immanuel Kant. ${ }^{13}$ The 
homo-duplex thinkers of the period, as 'university metaphysicians', Hunter argues, worked 'to explicate the Christian mysteries and reveal the pure concepts of morality and justice underlying the civil order'. More pointedly, in the constituent disciplines of early modern German metaphysical philosophy—'theology, Roman law, logic, ethics' - this mode of intellectual formation sought to 'cultivate', in its teachers and students alike, a 'metaphysical supra-civic consciousness'. ${ }^{14}$

In adding the dimension of 'pure subjectivity', Kant added substantially to what metaphysical philosophers took to be necessary in the formation of intellectuals. In short, he added the further necessity to always view objects of investigation 'in terms of ... unreconciled oppositions — between rationalism and voluntarism, intellectualism and empiricism', 'unreconciled oppositions', that demand to be reconciled with the higher self, such that any 'fully formed intellectual' will always find 'his or her own ethical impulse in the need to repeat the moment of their Kantian reconciliation'. ${ }^{15}$ In other words, Kant added to the already complex metaphysical use of the figure of homo-duplex the need to seek, through the higher self, 'the recovery of the a priori forms of subjectivity'. ${ }^{16}$ Vitally, this also meant adding the need to reject, as products of the lower, baser self, all attempts to govern humans by means of the sovereignty of the early-modern state, attempts at the heart of civil philosophy's attack on metaphysical philosophy, as we see in more detail later. To summarise:

university metaphysics ... rejected civil philosophy's uncoupling of the spheres of civil and

religious governance. Metaphysicians from Martinis to Kant refused to accept the indiffer-

ence of sovereign power to moral truth-thereby rejecting the autonomy of the political

-with Kant commenting on how 'terrible' it was that 'no philosopher has yet been able

to bring into agreement with morality ... the fundamental principles of the great societies

called states'. ${ }^{17}$

Cultural studies intellectuals of the ethical-must-be-moral type have their own way of fostering 'a metaphysical supra-civic consciousness', in themselves and others. Their version of the 'explication of the Christian mysteries' - a version heavily mediated by the aesthetichermeneutic and romantic elements we deal with shortly-is an explication of the mysteries of culture in terms of an understanding of morality, ethics and politics that definitely does not 'accept the indifference of sovereign power to moral truth' or 'the autonomy of the political'. This explication of culture has these intellectuals engage in their version of the revelation of 'the pure concepts of morality and justice underlying the civil order', and in the 'recovery' of a 'pure' form of subjectivity. In this way, they seek to reveal the ways in which the empowered impose their own-false, bourgeois-aesthetic on the culture of the disempowered, and to reveal the possibility of countering the morality behind this aesthetic, by restoring to these subjects their true morality, in the form of their true, oppositionalist 
cultural subjectivity. It is as if these intellectuals were pointedly agreeing with Kant about the need 'to bring into agreement with morality ... the fundamental principles of the great societies called states'.

A useful way to prepare the ground for the remainder of this genealogical outline, which deals with aesthetic-hermeneutic aspects, is to offer some unsettling remarks, from three other scholars, about the self-image produced by intellectuals who work in interdisciplinary enterprises. Tony Bennett portrays the self-image of many cultural studies intellectuals in terms of their ongoing capacity to think of their field as a force to 'displace or transcend [existing] disciplines ... [being] in some way inherently superior to them because of its interdisciplinarity'. ${ }^{18}$ John Frow suggests that the determination of cultural studies intellectuals to see their enterprise as interdisciplinary, to the point of being a fully fledged 'antidiscipline', serves as 'a self-validating claim'. ${ }^{19}$ These remarks can be amplified if we deploy JM Balkin's assessment of interdisciplinarity's effect on intellectuals more generally:

If disciplinarity is authoritarian, then perhaps interdisciplinarity is rebellious, even romantic. It is a form of intellectual martyrdom, a self-sacrifice against mindless authority; it offers a vision of independence of mind and spirit highly flattering to the average academic's self-conception. Interdisciplinary scholars are romantic rebels: they question authority by transgressing disciplinary boundaries. They are champions in the service of a greater truth. ${ }^{20}$

As noted earlier, Hunter doesn't take issue with cultural studies' claim to interdisciplinarity in toto, but with only one aspect of that claim, that whereby the field sets itself up as a project 'to transcend the limited conception of culture handed down by nineteenth-century aesthetics'. ${ }^{21}$ Hunter, insisting that the notion of culture be understood in terms of the notion of cultivation, focuses on cultural studies' attempts to expand the zone of culture from high culture, defined as the aesthetic pursuits of a social elite, to culture as a 'whole way of life'. He argues that two recent bodies of work make it difficult for the field to sustain its attempts to overturn aesthetics' denial of labour and politics as self-realising activities, that is, to have the economic and the political brought within the fold of culture as whole way of life.22

One of these two bodies of work seeks to re-describe ethics in terms of 'particular ethical orders' (Hunter cites Max Weber and Wilhelm Hennis) and in terms of 'Foucault's last investigations of late antique and early Christian sexual ethics'. ${ }^{23}$ This body of work, Hunter says, offers

an analysis of the ethical sphere that does not view it as an ideal or subjective domain; that is, one consisting of ideas and values in some sort of general relation to a counterposed sphere of material existence. Instead, the ethical sphere is held to consist of ways of conducting one's life-specific means for establishing the consistency of conduct and outlook that we associate with having a personality. ${ }^{24}$ 
Hunter uses this body of work as the base from which to re-describe the sphere of the aesthetic, 'as a distinctive way of actually conducting one's life-as a self-supporting ensemble of techniques and practices for problematizing conduct and events and bringing oneself into being as the subject of an aesthetic existence'. ${ }^{25}$

The other body of work central to Hunter's position seeks to move away from the idea that politics is composed of ideologies and interests. Hunter summarises two arguments in particular from this stable. The first is Barry Hindess's argument that political interests cannot be derived from some determining position, like an economic position, and should, instead, be understood as the product of 'specific institutions of political calculation, assessment and decision—trade unions, bureaucracies, parties, lobby groups'. The second, closely related, argument is one provided by Peter Miller and Nikolas Rose, to the effect that

the means by which human beings govern themselves and organize their economic lives do not arise from their political and economic existences, in the manner of ideologies. Rather, these means are contingent inventions and developments, emerging from the most diverse historical circumstances. ${ }^{26}$

These inventions and developments, Hunter tells us, "lead in no particular direction and realize no general form of "man" as a "species being", ${ }^{27}$

After insisting that this second body of work should lead us to analyse "political, ideological and cultural interests ... in terms of the available institutions of their formation and deployment ... without recourse to the notion of a privileged set of interests, such as that ascribed to the working class', Hunter suggests a manner of studying culture that is quite distinct from the sort of cultural studies so far presented. He urges his readers to reject the 'profoundly aesthetic critique of aesthetics' that this approach to the study of culture holds dear and take up instead 'a quite different reflection on the limits of the aesthetic domain, by beginning to treat it as one of the "contingencies that make us what we are". 28

These argumentative moves of Hunter's, by way of criticising cultural studies for its 'profoundly aesthetic critique of aesthetics', can usefully be employed to also criticise the idea of forming cultural studies intellectuals in line with a morality of engagement on behalf of the disempowered. Hunter's rejection of the notion that ethics must always be tied to a moral ideal, in favour of an understanding of ethics as a set of definite means for 'conducting' a life, or part of a life- 'an ensemble of techniques and practices' for making oneself act in one set of ways rather than another-can be adapted to suit the argument being propounded here. In this way, we need not attempt to blast from the water the notion of forming intellectuals in line with a particular morality, but simply ask that it, too, like the idea of a critique of aesthetics, be subjected to an interrogation about what is actually involved. The answer, at this level at least, is the same as it is for Hunter's interrogation of the 'critique of 
aesthetics' approach. What is actually involved in the notion of forming intellectuals in line with a particular morality is the deployment of a set of techniques and practices, in this case techniques and practices that would have one think and feel the morality in question; not as a 'false' break from one's 'true' self, but as one of the different aspects that make up a life. We can extend this point by also adapting both the arguments Hunter uses in favour of understanding political interests as products of 'specific institutions of political calculation, assessment and decision' and those he uses in favour of understanding 'the means by which human beings govern themselves' as 'contingent inventions and developments', which need to be carefully retrieved from their particular historical circumstances. In fact, we can directly apply Hunter's rejection of 'the notion of a privileged set of interests, such as that ascribed to the working class'. In our terms, this means rejecting the notion of a privileged set of interests ascribed to the disempowered and so rejecting the idea of a politics necessarily tied to this morality.

So, a fixed morality of engagement on behalf of the disempowered is not consistent with a politics associated with those 'contingent inventions and developments' of the modern state and related agencies that seek to address social, cultural and economic inequalities-pensions, superannuation schemes, health insurance schemes, schemes to help people with the costs of education, retraining schemes, charity arrangements, and so on-unless, of course, one wants to reject these in favour of illegal activities such as bank robbing and bombing, something, it is to be doubted, that even the most vehement cultural studies advocate of engagement on behalf of the disempowered has in mind. Similarly, no overarching ethic supposedly attached to this fixed morality is available, just the techniques and practices that would have one think and feel the morality. This should make it clear that no 'false' break from one's 'true' self is involved, only different aspects that make up a life. In other words, I am not suggesting that a cultural studies intellectual can't engage in effective political action towards the goal of increasing social, cultural and economic equality, only that it is highly unlikely that such a person could achieve such goals as a cultural studies intellectual. The techniques and practices central to being a cultural studies intellectual-the writing and arguing styles, the manner of speaking in the classroom and at conferences-are not necessarily the techniques and practices needed to deal with the state and associated agencies, as Bennett is at pains to point out in his Culture: A Reformer's Science. ${ }^{29}$ One would more likely benefit from the use of legal arguments, accounting techniques and the ability to juggle economic statistics.

In the remainder of Hunter's piece he fleshes out the above-summarised set of argumentative moves. Space limits our capacity to follow him too far in this meat-onto-bones exercise, but it is worth tracing at least some of his steps, particularly those that add substantially to the picture being painted of the ethical-must-be-moral type of cultural studies intellectual. 
Of particular benefit to this portrayal is Hunter's exploration of the role played by the late eighteenth-century German thinker, Friedrich Schiller, in formulating the aesthetichermeneutic component of this type. In setting the tone of his treatment of Schiller's contribution, particularly regarding the way this contribution operated through the appreciation of literature, Hunter first tells us that 'the means by which individuals have formed themselves as subjects of literary instruction and delight have not been constant' ${ }^{30}$ To reinforce this point he compares an earlier rhetorical means of handling literature-'the techniques permitting the sixteenth-century grammar-school boy to comb the classical canon for wise sayings, elegant turns of phrase, and ethical maxims, to store these as the commonplaces of his memory and copy book, and to retrieve them in times of oratorical need'-with Schiller's very different focus on the aesthetic function of literature. Schiller, Hunter argues, thought that individuals should 'learn to call themselves into aesthetic question by learning that true literary art is not immediately open to them, owing to a series of fundamental internal oppositions ... form and content, intellect and imagination, morality and the senses'. ${ }^{31}$ This creates the opportunity for individual readers to work on themselves, through a dialectical practice in which the self is at first affirmed, by being recognised in the literature, but then, crucially, is morally problematised, by being 'immediately converted into a symptom of aesthetic imbalance', unbalanced, that is, in terms of the 'fundamental oppositions' mentioned above. This is a process that never ends- the problematisation moves on by problematising itself_-such that the reader is trained into a state of permanent critique. What is more, it is a process that produces reforming individuals, always ready to 'critique' government, in the manner we saw above in the case of Kantian reconciliation, for their 'failure' to reconcile with moral norms, just as they must critique themselves for their own 'failure' to achieve aesthetic wholeness. ${ }^{32}$

The moral work done by this process, and the politics associated with it, clearly, are not restricted to an engagement with literature. In fact, Hunter says, despite cultural studies' determination to see the essential engagement being against 'bourgeois interests' (on behalf of the disempowered), the process can operate to give life to varying moral critiques, even to a moral critique of moralising. There is no one ultimate 'struggle', nor is there a hierarchy of 'struggles'. ${ }^{33}$ The personal, it seems, is indeed political, but in nothing like the way most cultural studies intellectuals take it to be. The personal is political only inasmuch as aspects of personalities can be formed in line with various political tasks on behalf of different moralities, not in being a permanent site of struggle, or a weapon of struggle, on behalf of some interest or other.

The connection between the homo-duplex, romantic and hermeneutic-aesthetic elements and the formation of cultural studies intellectuals who insist that ethics is necessarily moral should now be clear. These elements contribute to the possibility that such intellectuals 
can adopt a flexible approach to the morality involved, allowing it to take whatever shape is needed-which is sometimes even the shape of an anti-morality morality-to achieve the goal of empowering the disempowered (that these 'disempowered' are to be 'empowered' to join in the permanent critique is not directly mentioned by any of the cultural studies thinkers so heavily involved in fostering this type of intellectual). Hunter's work has been used to help break the nexus between ethics and morality — to call into question the 'equation' that assumes the 'equivalence of morality and ethos' - and to help propose a different way of understanding both ethics and politics. ${ }^{34}$ All that remains to be done in this section is to add one more small step to our outline of a genealogy of the ethical-must-be-moral type of cultural studies intellectual, one to do with the effect the work of thinkers like Schiller had on metaphysics, such that the crucial aesthetic element could flourish.

Hunter argues that the interventions of Schiller, often proposed by way of criticisms of Kant, need to be understood as part of a transformation of German metaphysics, one whereby its core transcendentalism was retained but, through Johann Gottlieb Fichte's and GWF Hegel's work, as well as through Schiller's, was reshaped. Hunter argues that it was reshaped into something

quite other than formal metaphysics ... a hybrid discourse in which an ethical regimen ... is 'transcendentalized' while nonetheless retaining an irreducibly practical core ...

[featuring] a fundamental dialectic between 'person' and 'condition' [with] a voluntary and practical character. ${ }^{35}$

In other words, an 'art of living' had emerged, one by which subjects were free to shape themselves, but chose to do so in line with the always-out-of-reach possibility of being true to each of their inner being, their history and their future. In choosing this path, that is, choosing to attempt to perfect themselves, subjects also chose an ethic of rejection-rejecting 'the "world" against which it was articulated ... a means by which individuals set themselves apart from "ordinary" existence and conduct themselves as subjects of a heightened form of being'. ${ }^{36}$

The ethical-must-be-moral type of cultural studies intellectual chooses the morality-driven ethic of engagement to achieve the goal of empowering the disempowered yet is never able to leave behind the ethic of withdrawal from the world of politics and economics. Hence, intellectuals of this type can juggle—indeed, thrive by juggling — a vital sense of permanent critique and a 'heightened form of being', a conviction, sometimes conscious, sometimes not, that they are in a position to pronounce not only on the best ways to empower the disempowered, but also on how it should be done. 


\section{- Civil philosophy as a Source of a Rival intellectual type}

In considering the extent to which civil philosophy is a source for the thinking behind this article's problematisation of the ethical-must-be-moral type of cultural studies intellectual, it is reasonable to treat civil philosophy as a distinct 'mode of intellectual formation'. By 'intellectual formation' I mean nothing so complex as the biological and psychological processes at work in any particular individual who has worked in the knowledge process as 'an intellectual'. Rather, it refers to the actual conditions, in so far as it is possible to determine them, by which such individuals, at particular times and in particular places, undertook their thinking, arguing and writing in one set of ways rather than another: the existing resources they used for their work; what they counted as evidence and how they went about using it; what they regarded as telling arguments and how they went about making them; how they regarded themselves; and, how they were and are regarded by others as they played their roles as intellectuals, especially their role in training their pupils. It is this set of factors for which the term 'mode of intellectual formation' is employed. Even when it is captured, as it often is within the history of thought literature, by terms like 'mindset', 'habit of mind' or 'cast of mind' it should still not be understood to be about each individual's psychological or biological make-up. ${ }^{37}$

We can begin our treatment of civil philosophy as a mode of intellectual formation by borrowing from English historian AL Rowse a thumbnail sketch of Thomas Hobbes's cast of mind. Rowse, himself borrowing from Croom Robertson, provides a glimpse of Hobbes's mindset when he insists that he was far more than an out-and-out deductivist: while his thought was characterised by 'large constructive ambition' it was always tempered by experience-'his abstract generalisations carry practical point, sometimes with a spike ... He is a commonsense plebeian, his main concern the practical direction of human conduct to the end of self-preservation'. ${ }^{38}$ While this is obviously a long way from being a detailed account of Hobbes's intellectual formation, let alone of his contribution to a civil philosophy mode of such formation, it does allow us to gain at least some idea of the habits of mind produced by the civil philosophy mode in the seventeenth century (and in the following centuries). We can see the importance of marshalling empirical evidence without excessive appeal to Plato or Aristotle (though under the influence of different ancient resources, a point to which we return shortly), and with it a concern for 'the practical direction of human conduct' in this world, usually with the aim of self-preservation but certainly without regard to the aim of 'explicating the Christian mysteries to reveal the pure concepts of morality and justice underlying the civil order', or the aim of 'cultivating a metaphysical supra-civic consciousness', or that of 'recovering the a priori forms of subjectivity'. 
Civil philosophy's rejection of the overwhelming influence of Plato and Aristotle needs further discussion. Where the homo-duplex metaphysical thinkers, bidding to continue and even extend the dominance of the Platonic/Aristotelian ideal of the 'higher self', sought to block the intellectual use of non-Platonic and non-Aristotelian resources, the civil philosophers were keen to explore all important ancient alternatives. This keenness saw them carefully consider what had been recovered of the thinking of one of Plato's and Aristotle's greatest contemporary opponents, Epicurus (341-271 BC). Epicurus believed that the search for human happiness involves an attempt to balance pleasure and pain, the two elemental emotional states with which we are born, as are all beasts. For him, rejecting the idea of the higher self in favour of a conception in which we balance a little reason and much passion on just the one level, much of our pain stems from our passions, both those associated directly with our attempts to satisfy our direct desires for food, sex, water and warmth, and those not so directly involved, especially our religious passions. ${ }^{39}$

The seventeenth-century revival of Epicureanism allowed various thinkers, but especially Hobbes and the German Samuel Pufendorf, to use Epicurus's conception of passionate man as a direct rival to the metaphysical philosophers' use of homo-duplex. We can see these thinkers' cast of mind very clearly in Hunter's re-creation of Pufendorf's Epicurean voluntarist version of what lies at the core of human interaction:

[Pufendorf] characterises natural man as a creature whose weakness ... necessitates sociality for survival but whose "vices render dealing with him risky and make great caution necessary to avoid receiving evil from him instead of good ... Many ... passions and desires are found in the human race unknown to the beasts, as, greed for unnecessary possessions, avarice, desire of glory and surpassing others, envy, rivalry and intellectual strife' ... Man's petulance, his capacity for giving and receiving offence, combined with his extraordinary capacity for violence, makes his natural condition a very dangerous one, particularly when one takes into account the great divisions in human beliefs and ways of life ... Man's life in the state of nature would thus indeed be miserable, unadorned, and short. It would not, however, be ungoverned by natural law or bereft of friendship as a primitive form of sociality. This is because man is indeed equipped by nature to know the natural law, even if he is not equipped to govern himself in accordance with it. ${ }^{40}$

The two dominant themes of civil philosophy intellectual formation mentioned above are present here: the marshalling of empirical evidence without recourse to the total authority of Aristotle or Plato, and the concern, in line with what little reason we do possess, for 'the practical direction of human conduct' in this world, with the aim of self-preservation. Also present is a means of understanding politics in line with Hunter's very different way of understanding it presented in the previous section. This alternative account of politics needs 
expansion, something we can straightforwardly do by tying it closely to the account developed by the twentieth-century jurist and political thinker, Carl Schmitt. His account, which we might designate as 'raw politics', is itself a development of the thinking of Hobbes, and perhaps also of Machiavelli. It is concerned with the natural human drive to distinguish friend from enemy, on any grounds, none of them necessary. ${ }^{41}$ Schmitt famously saw, as one of the outcomes of this drive, that humans on one side of the division seek to kill as many humans on the other as possible. As an account of politics-or, more strictly, a criterion by which to judge what is political as opposed to something else-it works just as well without taking it to this extreme, though it is salutary to always remember it as a possibility. Hunter says he owes at least some of his criticisms of romantic thinking to Schmitt's account of politics. He provides three reasons for making Schmitt's approach a pillar of his argument: one, Schmitt's 'account of the historical significance of political or "public" law ... whose restriction of sovereignty to the purely worldly domination of a territory he regards as affecting a fundamental "detheologisation" of politics'; two, 'his discussion of the "autonomising of politics" undertaken by the early modern political jurists—-their separation of the "security state" from the spheres of morality and economy'; three, his role in 'the "intellectual civil war" between civil and metaphysical philosophy', the fact that he 'deliberately targets post-Kantian "political Romanticism" for its treatment of historical politics as the manifestation of transcendental-subjective categories, thereby reducing the contestation between political enemies to an a-political debate over the good life'. ${ }^{42}$

To complete our picture of the civil philosophy mode of intellectual formation we would do well to take on board some of Hunter's remarks about the efforts of Pufendorf's pupil, Christian Thomasius, especially about his 1699 campaign against the intellectual comportment of the metaphysicians. Hunter insists that this campaign was nothing less than the ground-clearing stage of an attempt to build a different intellectual ethos, one 'suited to the jurists and politici of the desacralised state'. ${ }^{43}$ Both Pufendorf and Thomasius, Hunter reiterates, 'sought to destroy metaphysics so that they could transform practical philosophy in accordance with the political and juridical secularisation of civil governance'. This 'radical reorientation' meant that 'the civil sciences'-those set up in direct opposition to the disciplines of the metaphysicians-'eschewed revealed or transcendent objects and restricted themselves to empirically available ones. On the other hand, it dictated that the transcendent objects of theology ... were treated as objects of faith, completely inaccessible to natural philosophical knowledge'. ${ }^{44}$

\section{- Conclusion}

Two distinct types of intellectual have been presented. One of them, called here the ethicalmust-be-moral type, has been a central part of the cultural studies landscape from its British 
beginnings in the 1950s; the other one, called here the civil philosophy type, has had nothing like the same profile in the field. To re-emphasise the differences between these two types is our remaining task.

As we have seen, where the ethical-must-be-moral type of intellectual thinks and feels the morality of empowering the disempowered, insists that a politics flows from this, and insists that an ethics is subsumed within it, the civil philosophy type separates morality, politics and ethics. This rival type understands politics in terms of those 'specific institutions of political calculation, assessment and decision', that is, those 'contingent inventions and developments' involved in the processes 'by which human beings govern themselves'. It understands ethics as a set of definite means for 'conducting' a life, or part of a life, that is, as 'an ensemble of techniques and practices' for making oneself act in one set of ways rather than another, towards assembling a 'personality', or part, or parts, of one. In line with this, the civil philosophy type of intellectual brings morality into the same realm as politics and ethics, allowing it historical specificity-moral codes are what they are and must be understood in their own time and place, even when the time is long and the place is wide, as is the case with Christian codes of morality or those of other religions-but not allowing it a 'higher' status as something possibly eternal and universal.

Another key difference involves the way the two types of intellectual understand human individuals. For the ethical-must-be-moral type, working from its homo-duplex metaphysical roots, and thereby featuring the Platonic/Aristotelian ideal of the 'higher self', the individual is an aesthetically formed, romantic figure, even when the aesthetics involved portrays itself as anti-aesthetics. As such, this individual is in a state of permanent critique, against itself and against government. On the other hand, the civil philosophy type works with a more pessimistic picture, one in which an Epicurean account, balancing a little reason and much passion, has it that the individual is 'a creature whose weakness ... necessitates sociality for survival but whose "vices render dealing with him risky and make great caution necessary to avoid receiving evil from him instead of good"', and so on. This civil philosophy understanding of the human individual informs the other aspect of the alternative account of politics we have seen to be crucial to the civil philosophy type of intellectualthe Schmittian vision of 'raw politics'. This is a politics based on the natural human drive to distinguish friend from enemy, on any grounds.

Finally, where the ethical-must-be-moral type of intellectual seeks to foster 'a metaphysical supra-civic consciousness', in themselves and others, and to perform, as its version of the 'explication of the Christian mysteries', an explication of the mysteries of culture in terms of a nexus between morality, ethics and politics, the civil philosophy type, accepting 'the indifference of sovereign power to moral truth' and 'the autonomy of the political', attempts to build a different intellectual ethos. Pointedly statist, this ethos seeks to produce 'the jurists 
and politici of the desacralised state', with an emphasis on the separation of faith and knowledge.

Thanks to Barbara Evers, Jo Goodie, Ian Hunter, Gavin Kendall, Rachael Kitchens, Liam Stone, and two anonymous referees for their critical feedback on earlier drafts.

GARY WICKHAM is Associate Professor of Sociology at Murdoch University. His recent books are Understanding Culture: Cultural Studies, Order, Ordering, co-authored with Gavin Kendall (Sage, 2001); Rethinking Law, Society and Governance: Foucault's Bequest, co-edited with George Pavlich (Hart, 2001); and Using Foucault's Methods, co-authored with Gavin Kendall (Sage, 1999).

1. Graeme Turner, British Cultural Studies, second edition, Routledge, London, 1996, pp. 4, 1, 11

2. Turner, pp. $12-70$

3. Turner, pp. 12, 38-42

4. Cary Nelson, Paula A Treichler and Lawrence Grossberg, 'Cultural Studies: An Introduction', in Lawrence Grossberg, Cary Nelson and Paula A Treichler (eds), Cultural Studies, Routledge, New York, 1992, p. 1

5. Nelson, Treichler and Grossberg, pp. 1-6.

6. Nelson, Treichler and Grossberg, pp. 9-16.

7. Stuart Hall, 'Cultural Studies and its Theoretical Legacies', in Grossberg, Nelson and Treichler, pp. 277-94.

8. Hall, pp. 278,286

9. Hall, pp. $278,283$.

10. Ian Hunter, Culture and Government: The Emergence of Literary Education, Macmillan, London, 1988; Ian Hunter, Rethinking the School: Subjectivity, Bureaucracy, Criticism, Allen and Unwin, Sydney, 1994; Mary Poovey, Making a Social Body: British Cultural Formation 1830-1864 University of Chicago Press, Chicago, 1995; Tony Bennett, Culture: A Reformer's Science, Allen and Unwin, Sydney, 1998, p. 19

11. Ian Hunter, Rival Enlightenments: Civil and Metaphysical Philosophy in Early Modern Germany, Cambridge University Press, Cambridge, 2001; Ian Hunter, 'Aesthetics and Cultural Studies', in Grossberg, Nelson and Treichler, pp. 347-72.

12. Hunter, Rival Enlightenments, p. 20.

13. Hunter, Rival Enlightenments, p. x.

14. Hunter, Rival Enlightenments, p. 28.

15. Hunter, Rival Enlightenments, p. ix-x.

16. Hunter, Rival Enlightenments, p. 28
17. Hunter, Rival Enlightenments, p. 91.

18. Bennett, p. 19

19. John Frow, Cultural Studies and Cultural Value, Clarendon, Oxford, 1995.

20. JM Balkin, quoted in Douglas Vick, 'Interdisciplinarity and the Discipline of Law', Journal of Law and Society, vol. 31, no. 2, 2004 , p. 171.

21. Hunter, 'Aesthetics and Cultural Studies', p. 347.

22. Hunter, 'Aesthetics and Cultural Studies', pp. 347-8.

23. Hunter, 'Aesthetics and Cultural Studies', p. 348 24. Hunter, 'Aesthetics and Cultural Studies', p. 348 25. Hunter, 'Aesthetics and Cultural Studies', p. 348 26. Hunter, 'Aesthetics and Cultural Studies', p. 348

27. Hunter, 'Aesthetics and Cultural Studies', p. 348.

28. Hunter, 'Aesthetics and Cultural Studies', p. 349, quoting Foucault.

29. Bennett, p. 19

30. Hunter, 'Aesthetics and Cultural Studies', p. 350

31. Hunter, 'Aesthetics and Cultural Studies', p. 350

32. Hunter, 'Aesthetics and Cultural Studies', pp. 352-5.

33. Hunter, 'Aesthetics and Cultural Studies', pp. 356-8.

34. Hunter, 'Aesthetics and Cultural Studies', p. 368

35. Hunter, 'Aesthetics and Cultural Studies', pp. 360-1.

36. Hunter, 'Aesthetics and Cultural Studies', pp. 360-1.

37. One of the best examples is JGA Pocock's seminal The Ancient Constitution and the Feudal Law: A Study of English Historical Thought in the Seventeenth Century: A Reissue with a Retrospect, Cambridge University Press, Cambridge, 1987. 
38. AL Rowse, Four Caroline Portraits: Thomas Hobbes, Henry Marten, Hugh Peters, John Selden,

Duckworth, London, 1993, p. 23.

39. Epicurus, The Essential Epicurus, trans., intro.

Eugene O'Connor, Prometheus Books, New York, 1993; Epicurus, The Epicurus Reader, ed. and trans. Brad Inwood and LP Gerson, intro. DS Hutchinson, Hacket Publishing Co. Indianapolis, 1994. For more on Epicurean thought, especially as it was understood in the seventeenth century, see MJ Osler (ed.), Atoms, Pneuma, and Tranquillity: Epicurean and Stoic Themes in European Thought, Cambridge University Press, Cambridge, 1991.

40. Hunter, Rival Enlightenments, pp. 171-2, quoting Pufendorf.
41. Carl Schmitt, The Concept of the Political, trans., notes, intro. George Schwab, afterword Leo Strauss, Princeton University Press, Princeton, 1976 [1927]. See also Gershon Weiler, From Absolutism to Totalitarianism: Carl Schmitt on Thomas Hobbes, Hollowbrook, Durango, Colorado, 1994, for an argument that Schmitt's vision of politics was more consistent with Guicciardini's thinking than with that of his contemporary, Machiavelli (pp. 30-3), and for an argument that it is not necessarily consistent with Hobbes's thinking (passim).

42. Hunter, Rival Enlightenments, p. 11

43. Hunter, Rival Enlightenments, pp. 9-10.

44. Hunter, Rival Enlightenments, pp. 89-90. 